\title{
Review of Paravertebral Regional Techniques utilised for Thoracic Surgery in a Tertiary Cardiothoracic Centre
}

\author{
Yap W.L., Bhawnani A., Palmer K., McKevith J., Agarwal S. \\ Liverpool Heart and Chest Hospital, Anaesthetic Department, Liverpool, United Kingdom
}

\section{Background}

There is a wide spectrum of analgesic techniques utilised for thoracic surgery which is dependent on patient profile and influenced by anaesthetic and surgical preference or skill mix. ${ }^{1}$ Our objective was to compare ultrasound(USS) guided paravertebral(PVB) to landmark guided PVB in videoassisted thoracoscopy (VAT) and thoracotomy procedures in our unit.

\section{Methods}

Data was collected over a 4 week period in November 2014. We looked at the type surgery performed, intraoperative and post-operative analgesia usage and type of regional technique performed. Perioperative data was collected prospectively by the primary anaesthetist and recovery nurse. Post-operative analgesia usage was collected retrospectively through the hospital's electronic documentation system.

\section{Results}

There were 33 cases in total. 23 VAT procedures and 10 thoracotomies with 14 receiving USS guided PVB block and 19 receiving landmark PVB block. Mean duration for block performance was 7.5 $( \pm 3.7)$ minutes (USS) and 6.6( \pm 2.9$)$ minutes (landmark).

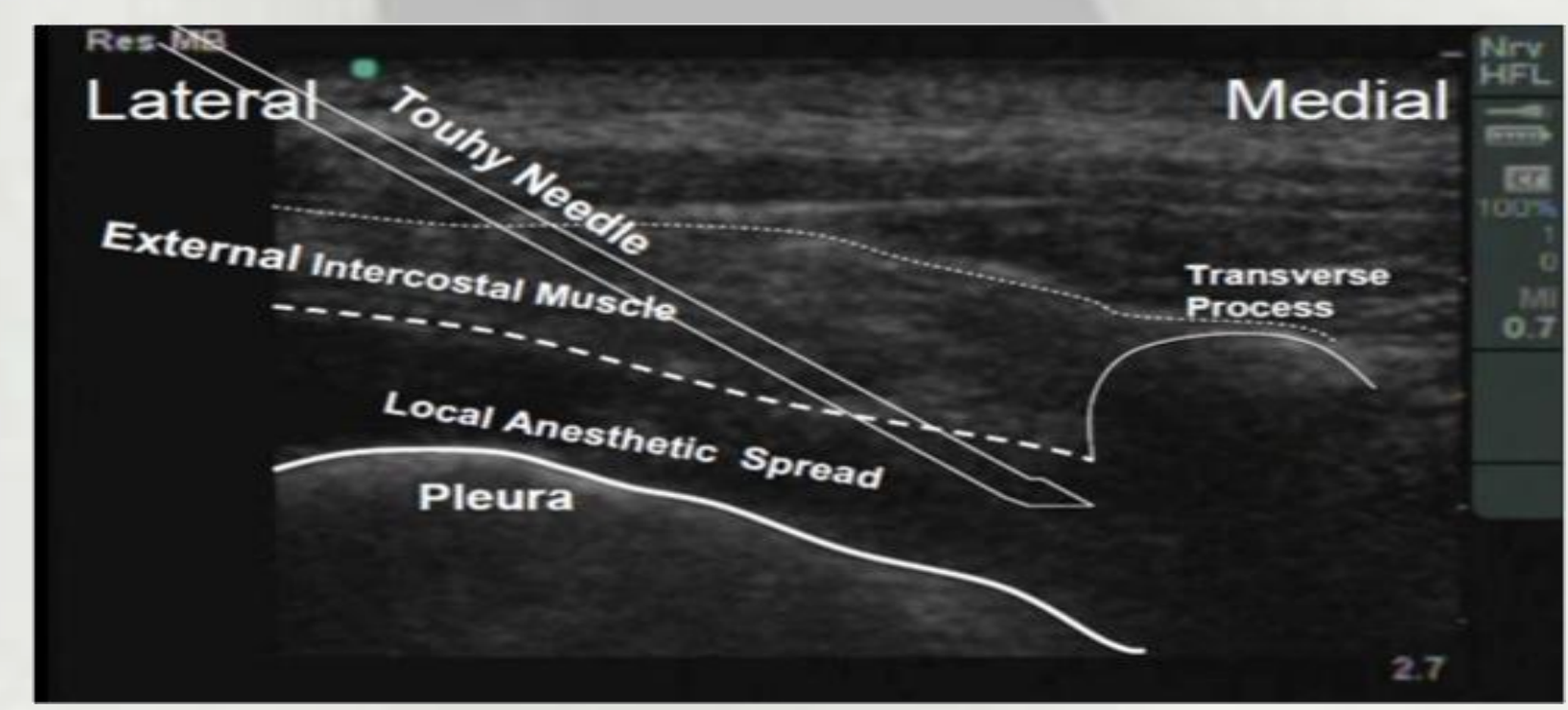

Figure 1: A view of Ultrasound Guided Paravertebral Block. Taken from http://www.utswanesthesia.com/regional/?page_id=420
Mean morphine consumption in first 24 hours post surgery was $25.7( \pm 19.6) \mathrm{mg}$ (USS) and 44.7( \pm 25.0$)$ $\mathrm{mg}$ (landmark). There were 2 complications (2 pleural tap) associated with landmark PVB block.

\begin{tabular}{|c|c|c|c|c|}
\hline & \multicolumn{2}{|c|}{ Ultrasound guided PVB block } & \multicolumn{2}{|c|}{ Landmark PVB block } \\
\hline & Value & $\begin{array}{c}\text { Standard } \\
\text { Deviation }\end{array}$ & Value & $\begin{array}{l}\text { Standard } \\
\text { Deviation }\end{array}$ \\
\hline No. of Patients & 14 & & 19 & \\
\hline $\begin{array}{l}\text { Mean Duration } \\
\text { (minutes) }\end{array}$ & 7.5 & \pm 3.7 & 6.6 & \pm 2.9 \\
\hline $\begin{array}{l}\text { Mean } \\
\text { Morphine }\end{array}$ & $\mathrm{s}^{2}$ & & & \\
\hline $\begin{array}{l}\text { Consumption } \\
\text { in First } 24 \text { hrs } \\
\text { (miligrams) }\end{array}$ & 25.7 & \pm 19.6 & 44.7 & \pm 25.0 \\
\hline Complications & 0 & & pleural taps & \\
\hline
\end{tabular}

Table 1: Comparison of Paravertebral Regional Anaesthesia Techniques utilised for Thoracic Surgery

\section{Conclusion}

Mean morphine consumption was lower in the USS guided PVB group and rates of complication were higher in landmark PVB group. This was a snapshot audit of our practice and sample size was small, we conclude that USS guided PVB block is an alternative to landmark PVB block with similar duration of procedure. There is limited comparison literature ${ }^{2}$ but we feel that USS guided technique in experienced hands and under direct vision would reliably position a needle in the PVB space and hence be safer and improve block success rates. This will help justify a randomized study of USS guided PVB block versus landmark PVB block in patients undergoing thoracic surgery.

Reference

1. Pennefather SH, McKevith J. Pain Management After Thoracic Surgery. Principles and Practice of Anesthesia for Thoracic Surgery. Springer Science + Business Media; 2011

2. Shelley B, Macfie A. Where now for thoracic paravertebral blockade? Anaesthesia. Wiley-Blackwell; 2012 Nov 7;67(12):1317-20 